\title{
PRODUCTS OF RADIAL DERIVATIVE AND WEIGHTED COMPOSITION OPERATORS FROM WEIGHTED BERGMAN-ORLICZ SPACES TO WEIGHTED-TYPE SPACES
}

\author{
ZHI-JIE JIANG AND XIAO-FENG WANG
}

\begin{abstract}
Let $H\left(\mathbb{B}^{n}\right)$ be the space of all holomorphic functions on the unit ball $\mathbb{B}^{n}$ of $\mathbb{C}^{n}, \varphi$ a holomorphic self-map of $\mathbb{B}^{n}, u \in H\left(\mathbb{B}^{n}\right)$, and $\Re$ the radial derivative operator on $H\left(\mathbb{B}^{n}\right)$. Two operators on $H\left(\mathbb{B}^{n}\right)$ are defined by $\Re W_{u, \varphi} f(z)=\Re(u(z) f(\varphi(z)))$ and $W_{u, \varphi} \Re f(z)=u(z) \Re f(\varphi(z))$, which are called the products of radial derivative operators and weighted composition operators. In this paper, the boundedness and compactness of the operators $\Re W_{u, \varphi}$ and $W_{u, \varphi} \Re$ from weighted Bergman-Orlicz spaces to a class of weighted-type spaces are characterized.
\end{abstract}

Mathematics subject classification (2010): Primary 47B38, Secondary 47B33, 47B37.

Keywords and phrases: Weighted Bergman-Orlicz spaces, weighted composition operators, radial derivative operators, products of radial derivative and weighted composition operators, weighted-type spaces.

\section{REFERENCES}

[1] C. C. Cowen, B. D. MACCluer, Composition operators on spaces of analytic functions, CRC Press, 1995.

[2] R. A. Hibschweiler, N. Portnoy, Composition followed by differentiation between Bergman and Hardy spaces, Rocky Mountain J. Math. 35 (3) (2005), 843-855.

[3] S. JANSON, Generalizations of Lipschitz spaces and an application to Hardy spaces and bounded mean oscillation, Duke Math. J. 47 (4) (1980), 959-982.

[4] Z. J. JiAng, S. STEvić, Compact differences of weighted composition operators from weighted Bergman spaces to weighted-type spaces, Appl. Math. Comput. 217 (7) (2010), 3522-3530.

[5] Z. J. JiAnG, On a class of operators from weighted Bergman spaces to some spaces of analytic functions, Taiwan. J. Math. Soc. 15 (5) (2011), 2095-2121.

[6] Z. J. JIANG, Weighted composition operators from weighted Bergman spaces to some spaces of analytic functions on the upper half plane, Util. Math. 93 (2014), 205-212.

[7] S. Li, S. STEVIĆ, Composition followed by differentiation between Bloch type spaces, J. Comput. Anal. Appl. 9 (2) (2007), 195-206.

[8] S. Li, S. STEVIĆ, Weighted composition operators from Bergman-type spaces into Bloch spaces, Proc. Indian Acad. Sci. Math. Sci. 117 (3) (2007), 371-385.

[9] S. Li, S. STEVIĆ, Weighted composition operators from $\alpha$-Bloch space to $H^{\infty}$ on the polydisk, $\mathrm{Nu}-$ mer. Funct. Anal. Optimization. 28 (7) (2007), 911-925.

[10] S. Li, S. STEvić, Composition followed by differentiation from mixed norm spaces to $\alpha$-Bloch spaces, Sb. Math. 199 (12) (2008), 1847-1857.

[11] S. LI, S. STEVIĆ, Weighted composition operators between $H^{\infty}$ and $\alpha$-Bloch spaces in the unit ball, Taiwan. J. Math. Soc. 12 (2008), 1625-1639.

[12] S. Li, S. STEvić, Weighted composition operators from Zygmund spaces into Bloch spaces, Appl. Math. Comput. 206 (2) (2008), 825-831.

[13] S. Li, S. STEvić, Composition followed by differentiation between $H^{\infty}$ and $\alpha$-Bloch spaces, Houston J. Math. 35 (1) (2009), 327-340.

[14] S. Li, S. STEvić, Products of composition and differentiation operators from Zygmund spaces to Bloch spaces and Bers spaces, Appl. Math. Comput. 217 (2010), 3144-3154. 
[15] S. LI, S. STEvić, Weighted differentiation composition operators from the logarithmic Bloch space to the weighted-type space, Analele Stiint. Univ. Ovidius C. 24 (3) (2016), 223-240.

[16] S. OHNo, Weighted composition operators between $H^{\infty}$ and the Bloch space, Taiwan. J. Math. Soc. 5 (3) (2001), 555-563.

[17] S. OHNo, Products of composition and differentiation on Bloch spaces, Bull. Korean Math. Soc. 46 (6) (2009), 1135-1140.

[18] B. Sehba, S. STEvić, On some product-type operators from Hardy-Orlicz and Bergman-Orlicz spaces to weighted-type spaces, Appl. Math. Comput. 233 (2014), 565-581.

[19] B. SEHBA, Duality for large Bergman-Orlicz spaces and boundedness of Hankel operators, https://arxiv.org/pdf/1501.03416v1.

[20] B. Sehba, Derivatives characterization of Bergman-Orlicz spaces and applications, https://arxiv.org/abs/1610.01954.

[21] A. K. Sharma, Z. ABBAS, Weighted composition operators between weighted Bergman-Nevanlinna and Bloch-type spaces, Appl. Math. Sci. 41 (4) (2010), 2039-2048.

[22] A. K. Sharma, Products of composition multiplication and differentiation between Bergman and Bloch type spaces, Turkish. J. Math. 35 (2011), 275-291.

[23] S. STEVIĆ, Essential norms of weighted composition operators from the $\alpha$-Bloch space to a weightedtype space on the unit ball, Abstr. Appl. Anal. 2008 (2008), Article ID 279691, 11 pages.

[24] S. STEVIĆ, Norms of some operators from Bergman spaces to weighted and Bloch-type space, Util. Math. 76 (2008), 59-64.

[25] S. STEvić, Norm of weighted composition operators from Bloch space to $H^{\infty}$ on the unit ball, Ars Combin. 88 (2008), 125-127.

[26] S. STEVIĆ, On a new integral-type operator from the weighted Bergman space to the Bloch-type space on the unit ball, Discrete Dyn. Nat. Soc. 2008 (2008), Article ID 154263, 14 pages.

[27] S. STEviĆ, Products of composition and differentiation operators on the weighted Bergman space, Bull. Belg. Math. Soc. 16 (2009), 623-635.

[28] S. STEVIĆ, On an integral-type operator from logarithmic Bloch-type and mixed-norm spaces to Bloch-type spaces, Nonlinear Anal. TMA 71 (2009), 6323-6342.

[29] S. STEVIĆ, Weighted differentiation composition operators from mixed-norm spaces to weighted-type spaces, Appl. Math. Comput. 211 (2009), 222-233.

[30] S. STEVIĆ, Weighted composition operators from weighted Bergman spaces to weighted-type spaces on the unit ball, Appl. Math. Comput. 212 (2009), 499-504.

[31] S. STEVIĆ, Norm of weighted composition operators from $\alpha$-Bloch spaces to weighted-type spaces, Appl. Math. Comput. 215 (2009), 818-820.

[32] S. STEVIĆ, Norm and essential norm of composition followed by differentiation from $\alpha$-Bloch spaces to $H^{\infty}$, Appl. Math. Comput. 207 (2009), 225-229.

[33] S. STEVIĆ, On operator $P_{\varphi}^{g}$ from the logarithmic Bloch-type space to the mixed-norm space on unit ball, Appl. Math. Comput. 215 (2010), 4248-4255.

[34] S. STEVIĆ, Composition followed by differentiation from $H^{\infty}$ and the Bloch space to $n$-th weightedtype spaces on the unit disk, Appl. Math. Comput. 216 (2010), 3450-3458.

[35] S. STEVIĆ, Weighted iterated radial composition operators between some spaces of holomorphic functions on the unit ball, Abstr. Appl. Anal. 2010 (2010), Article ID 801264, 14 pages.

[36] S. STEVIĆ, Weighted differentiation composition operators from $H^{\infty}$ and Bloch spaces to $n$-th weighted-type spaces on the unit disk, Appl. Math. Comput. 216 (2010), 3634-3641.

[37] S. STEVIĆ, Weighted differentiation composition operators from the mixed-norm space to the n-th weigthed-type space on the unit disk, Abstr. Appl. Anal. 2010 (2010), Article ID 246287, 15 pages.

[38] S. STEVIĆ, R. P. AGARWAL, Weighted composition operators from logarithmic Bloch-type spaces to Bloch-type spaces, J. Inequal. Appl. 2009 (2009), Article ID 964814, 21 pages.

[39] S. Stević, Z. J. JiAng, Differences of weighted composition operators on the unit polydisk, Siberian Math. J. 52 (2) (2011), 454-468.

[40] S. Stević, A. K. Sharma, Iterated differentiation followed by composition from Bloch-type spaces to weighted BMOA spaces, Appl. Math. Comput. 218 (2011), 3574-3580.

[41] S. Stević, A. K. Sharma, A. Bhat, Products of multiplication composition and differentiation operators on weighted Bergman spaces, Appl. Math. Comput. 217 (2011), 8115-8125.

[42] S. Stević, A. K. Sharma, A. Bhat, Essential norm of multiplication composition and differentiation operators on weighted Bergman spaces, Appl. Math. Comput. 218 (2011), 2386-2397. 
[43] S. STEvić, S. I. UEKI, Weighted composition operators and integral-type operators between weighted Hardy spaces on the unit ball, Discrete Dyn. Nat. Soc. 2009 (2009), Article ID 952831, 20 pages.

[44] W. YANG, W. YAN, Generalized weighted composition operators from area Nevanlinna spaces to weighted-type spaces, Bull. Korean Math. Soc. 48 (6) (2011), 1195-1205.

[45] K. ZHU, Spaces of holomorphic functions in the unit ball, Springer, New York, 2005. 